\title{
EVOLUTION OF MICROSTRUCTURE IN Ti15Mo ALLOY DEFORMED BY HIGH PRESSURE TORSION DURING LINEAR HEATING
}

\author{
Kristína BARTHA ${ }^{1}$, Josef STRÁSKÝ ${ }^{1}$, Jozef VESELÝ1 ${ }^{1}$, Veronika POLYAKOVA², \\ Irina SEMENOVA², Miloš JANEČEK ${ }^{1}$ \\ ${ }^{1}$ Department of Physics of Materials, Charles University, Prague, Czech Republic, EU, \\ kristina.bartha@met.mff.cuni.cz
}

${ }^{2}$ Institute of Physics of Advanced Materials, Ufa State Aviation Technical University, Ufa, Russian Federation

https://doi.org/10.37904/metal.2019.764

\begin{abstract}
The influence of severe plastic deformation on ongoing phase transformations in metastable $\beta$-Ti alloy Ti15Mo was investigated in-situ during linear heating by electrical resistance and complemented by ex-situ microstructure observations using transmission electron microscopy. Several non-monotonic regions in the temperature dependence of electrical resistance were identified and associated with corresponding phase transitions, namely the reversible diffusionless shuffle transformation of athermal $\omega$ phase, followed first by diffusion controlled growth of isothermal $\omega$ phase and subsequently its continuous dissolution. Formation of $\alpha$ phase at high temperature is associated with increase of the electrical resistance. The influence of severe plastic deformation on the phase transformations sequence is discussed in detail. For ex-situ microstructural observations different conditions were selected based on electrical resistance measurement. It was revealed, that lattice defects introduced by severe plastic deformation strongly influence the phase transitions during heating of the alloy.
\end{abstract}

Keywords: Metastable $\beta$ Ti alloy, high pressure torsion, phase transformations, microstructure, electrical resistance

\section{INTRODUCTION}

Titanium alloys are known to be attractive materials for numerous industrial applications. High strength, low density and excellent corrosion resistance provide a large potential for a variety of applications in automobile and airspace industry [1]. Due to a low elastic modulus some Ti alloys are also widely used in orthopedics and implantation surgery [2].

Pure titanium is an allotropic material which undergoes a phase transformation at $882^{\circ} \mathrm{C}$ from the low-temperature $\alpha$ phase (hexagonal close-packed structure) to the high-temperature $\beta$ phase (body-centered cubic) [3].

In recent years, the main interest has been focused on development and investigation of a group of metastable $\beta$-Ti alloys. These alloys contain sufficient amount of $\beta$ stabilizing elements (e.g. Mo, $\mathrm{V}, \mathrm{Fe}, \mathrm{Nb}$ ) which can suppress the martensitic $\beta \rightarrow \alpha$ transformation and retain the high temperature $\beta$ phase in a thermodynamically metastable state even at room temperature after quenching [4]. A series of non-equilibrium phase transformations may occur in these alloys, which, if properly controlled, may influence the microstructure and mechanical properties of the material. In some metastable $\beta$-Ti alloys, tiny nanometer-sized particles of metastable $\omega$ phase may form during quenching. The $\omega$ phase has hexagonal structure (not close-packed) and belongs to the $P 6 / \mathrm{mmm}$ space group [5]. It is formed by a reversible displacive shuffle transformation [6] and referred to as $\omega$ athermal $\left(\omega_{\text {ath }}\right)$. Athermal $\omega$ particles are coherent with $\beta$ matrix [7] and have a form of prolate spheroids. By ageing to higher temperatures (above $\sim 150{ }^{\circ} \mathrm{C}$, depending on the chemical composition of the alloy), when the diffusion becomes dominant, $\omega$ particles start to grow irreversibly and form so called $\omega$ isothermal phase $\left(\omega_{\text {iso }}\right)$. These particles are more chemically stabilized [8] and can serve as preferential 
nucleation sites for $\alpha$ phase particles during further annealing at suitable temperatures (above $400{ }^{\circ} \mathrm{C}$ ); therefore, the ultimately equilibrium $\alpha+\beta$ composition can be achieved $[9,10]$.

Severe plastic deformation (SPD) is an attractive method which introduces a high density of lattice defects into the bulk material and causes fragmentation of its microstructure and significant grain size reduction up to the submicrometer or even nanometer range [11-13]. One of the most popular methods of SPD is the high pressure torsion (HPT). It proved to be the most effective technique of grain refinement due to the introduction of extremely high plastic strain by torsional deformation [14,15].

In our previous studies phase transitions have been thoroughly investigated in several coarse-grained metastable $\beta$-Ti alloys (both single- and polycrystals) using several experimental techniques (microscopy, $X$-ray diffraction, electrical resistance, etc.) $[16,17]$. Recently, we have focused on the influence of SPD on the kinetics of ongoing phase transformation, in particular on the precipitation of a phase [18]. However, a detail study addressing all aspects of the influence of SPD on phase transitions is still missing. In order to fill this gap, we have selected a simple binary metastable $\beta$-Ti alloy Ti15Mo and employed in-situ electrical resistance measurement complemented by ex-situ observation of the microstructure in selected conditions by transmission electron microscopy to assess the details of the kinetics of phase transitions in severely deformed material.

\section{EXPERIMENTAL}

Ti15Mo alloy, which was subject of the investigation, was supplied by Carpenter, Co, USA in a form of rods with the diameter of $10 \mathrm{~mm}$. The supplied rod was solution treated at $810^{\circ} \mathrm{C}$ for 4 hours. Cylindrical specimens with height of approximately $5 \mathrm{~mm}$ were cut from the solution treated (ST) material (hereafter referred to as undeformed condition). These specimens were first pressed with a high pressure of $6 \mathrm{GPa}$ to double their diameter. HPT deformation was subsequently performed at room temperature (RT) and the same pressure by a single turn at USATU Ufa, Russian Federation. The resulting HPT-deformed samples had a shape of discs with the diameter of $20 \mathrm{~mm}$ and approximate height of $1 \mathrm{~mm}$.

The measurement of electrical resistance was performed using a standard four-point method employing a selfconstructed apparatus. The voltage and electrical current were measured simultaneously using nanovoltmeter Keithley 2182 and SourceMeter Keithley 2400 devices, respectively. The relative error of such a measurement is lower than $10^{-4}$ within each measured point and acquisition rate is two experimental values/second. The details of the apparatus and the measurement are given elsewhere [19]. The measurement was performed insitu during linear heating with the heating rate of $5^{\circ} \mathrm{C} / \mathrm{min}$ from room temperature up to $750{ }^{\circ} \mathrm{C}$.

Thermal treatment to selected temperatures based on results of the measurement of electrical resistance was carried out in a furnace with the same heating rate of $5{ }^{\circ} \mathrm{C} / \mathrm{min}$. During heating the specimens were sealed in a quartz tube filled with $\mathrm{Ar}$ to prevent contamination. After reaching the desired temperature, the specimens were immediately quenched in water.

Post mortem microstructure observations were performed using transmission electron microscope (TEM) Jeol JEM 2200 FS operated at the acceleration voltage of $200 \mathrm{kV}$. Thin foils for TEM observations were prepared from the periphery part of the HPT-deformed sample (where the deformation reaches its highest values; $\varepsilon_{v M}$ 36) by twin-jet electro-polishing (TENUPOL-5) unit at the temperature of $-20^{\circ} \mathrm{C}$ and finished by low voltage $\mathrm{Ar}$ ion milling using Leica EM RES102 ion polisher.

\section{RESULTS AND DISCUSSION}

The evolution of the relative electrical resistance with temperature for undeformed and HPT material is shown in Figure 1 (note that absolute electrical resistivity cannot be determined due to a complex shape of the sample) [20]. The relative electrical resistance was calculated by dividing the measured resistance by the 
reference value of the electrical resistance at the temperature of $40{ }^{\circ} \mathrm{C}$. The solid and dashed line represent the evolution of the relative electrical resistance of the undeformed and HPT-deformed Ti15Mo alloy, respectively. An unexpected behavior consisting of several stages of monotonic dependence of the electrical resistance on the temperature were found. Note, that similar behavior was observed in our previous work by Zháňal et al. [17] on coarse-grained Ti15Mo alloy and the microstructure changes controlling the behavior of electrical resistance in individual temperature ranges were discussed in detail.

In the first stage (from RT to $250{ }^{\circ} \mathrm{C}$ ) the decrease of the relative electrical resistance, which outweights the phonon scattering effect, was observed and attributed to the dissolution of the $\omega_{\text {ath }}$ particles [17]. The continuous dissolution of $\omega_{\text {ath }}$ precipitates during heating is accompanied by the partial release of the elastic strain

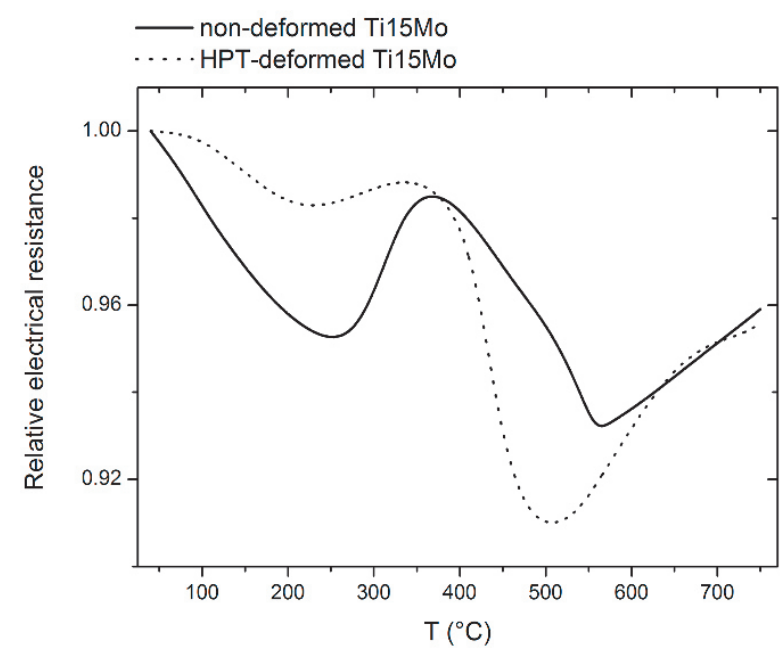

Figure 1 Temperature dependence of the relative electrical resistance of the undeformed (solid line) and HPT-deformed (dashed line) Ti15Mo alloy field formed originally during quenching around $\omega_{\text {ath }}$ precipitates and results in easier electron drift in the $\beta$ matrix [21]. As a result, the electrical resistance decreases with increasing temperature. The decrease of electrical resistance in HPT material is smaller due to the high density of lattice defects introduced to the material by severe plastic deformation. These defects act as additional scattering centers for electrons even after dissolution of the $\omega_{\text {ath }}$ phase.

The second stage (from $250^{\circ} \mathrm{C}$ to $365^{\circ} \mathrm{C}$ ) is characterized by an increase of the relative electrical resistance with increasing temperature and is related to the formation and growth of $\omega$ iso precipitates [22]. Both the formation and growth of these precipitates result in increasing amount of $\beta / \omega$ interfaces [23] which represent additional obstacles for electron drift, and thus, together with the phonon contribution, contribute to the increase of the electrical resistance in this stage.

The third stage (from $365{ }^{\circ} \mathrm{C}$ to $560{ }^{\circ} \mathrm{C}$ ) represents a decrease of the relative electrical resistance in both undeformed and HPT samples. It is caused by decreasing amount of $\beta / \omega$ interfaces due to simultaneous

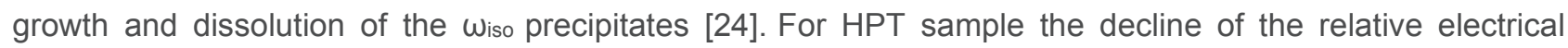
resistance is more pronounced. Besides the dissolution of the $\omega_{\text {iso }}$ phase, recovery of defects and possible recrystallization of the microstructure enhanced by the presence of lattice defects may play a significant role in deformed material. A complete dissolution of the $\omega_{\text {iso }}$ phase at $560{ }^{\circ} \mathrm{C}$ reported also in [17] is accompanied by an abrupt change in the monotonicity of the evolution of electrical resistance with temperature. The above mentioned change is also achieved in HPT-deformed material; however, it is shifted to lower temperatures. This may be attributed to shifted $\beta \rightarrow$ a transformation to lower temperatures in HPT-deformed material [18].

In the fourth stage (from $560^{\circ} \mathrm{C}$ to $750{ }^{\circ} \mathrm{C}$ ) an increase of the electrical resistance of the undeformed material is almost linear, suggesting that the nucleation and growth of the a phase has only a limited effect on the electrical resistance due to its relatively low volume fraction and large particle size. On the other hand, heating of the HPT-deformed sample shows a small peak between $600{ }^{\circ} \mathrm{C}$ and $700{ }^{\circ} \mathrm{C}$. This can correlate with the increased volume fraction of a phase compared to the undeformed counterpart; the deformation and induced lattice defects enhance the precipitation of the a phase due to preferential nucleation of the $\alpha$ phase at defects and accelerated growth due to enhanced diffusion along lattice defects [25]. The decrease of the slope of the relative electrical resistance curve after heating to temperature above $650{ }^{\circ} \mathrm{C}$ of the HPT sample can be associated with the dissolution of the a phase in the vicinity of the $\beta$-transus temperature. 
For further investigation of the microstructure post mortem in HPT-deformed material three characteristic temperatures were selected based on the behavior of electrical resistance at $350{ }^{\circ} \mathrm{C}, 500{ }^{\circ} \mathrm{C}$, and $650{ }^{\circ} \mathrm{C}$.

Figure 2 shows TEM bright field images of HPT samples after heating to three selected temperatures of $350{ }^{\circ} \mathrm{C}, 500{ }^{\circ} \mathrm{C}$, and $650^{\circ} \mathrm{C}$, respectively. The HPT-deformed sample heated to $350^{\circ} \mathrm{C}$ in Figure 2 (a) contains a heavily deformed and ultra-fine grained (UFG) structure. Figure 2 (b) representing the HPT sample heated to the temperature of $500{ }^{\circ} \mathrm{C}$ indicates that the microstructure remains UFG, however, small grains of the $\alpha$ phase are already visible. The presence of the a phase was also proved by X-ray diffraction [20] and are published elsewhere [26]. The sample heated to $650{ }^{\circ} \mathrm{C}$ shows a recovered, but still UFG microstructure containing grains of $\beta$ and $\alpha$ phase with the grain size $\sim 200 \mathrm{~nm}$ (note the lower magnification in Figure 2 (c) compared with Figures 2 (a) and (b)).
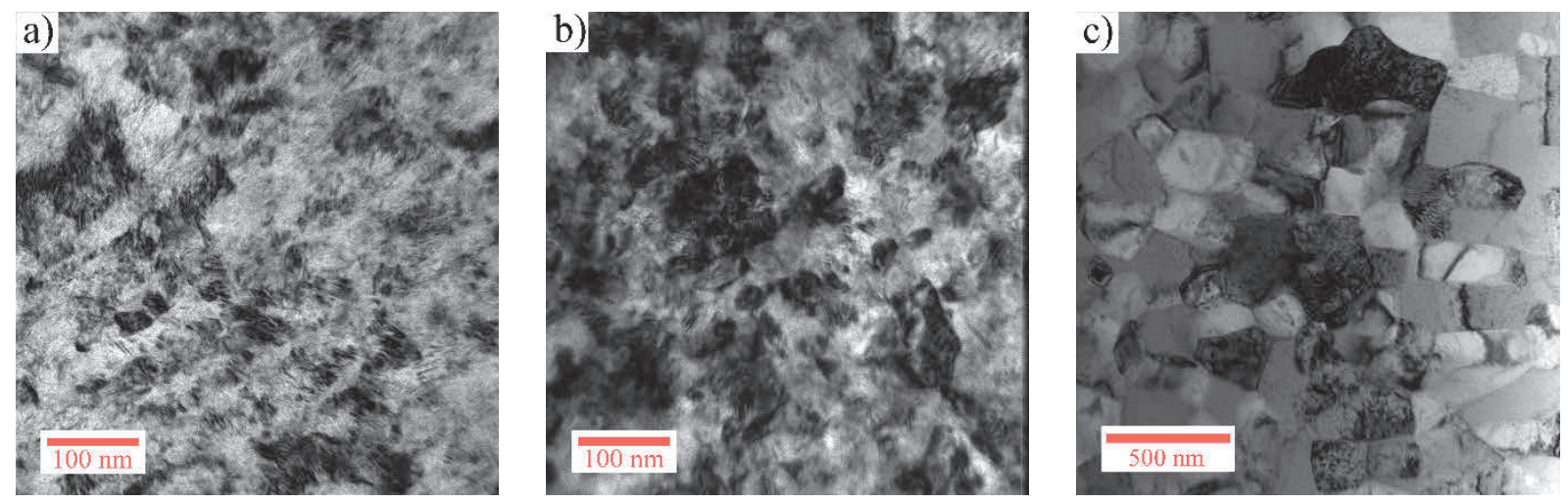

Figure 2 TEM bright field image of the HPT-deformed Ti15Mo alloy (a) heated to temperature $350{ }^{\circ} \mathrm{C}$,

(b) heated to temperature $500{ }^{\circ} \mathrm{C}$, (c) heated to temperature $650{ }^{\circ} \mathrm{C}$ (note the lower magnification in this case)

\section{CONCLUSIONS}

The influence of severe plastic deformation on phase transformations occurring in a metastable $\beta$-Ti alloy Ti15Mo during heating was investigated in-situ by electrical resistance measurements and complemented by ex-situ microstructure observations using transmission electron microscopy. The following conclusions may be drawn from this experimental study:

- HPT deformation introduced a high density of lattice defects into the material and resulted in a strong grain refinement.

- The evolution of the electrical resistance upon heating is complex - it consists of several stages with alternating positive (normal behavior) and negative slope (inverse dependence).

- $\quad$ Lattice defects introduced by severe plastic deformation influence the phase transformations - they accelerate the precipitation (both nucleation and growth) of the $\alpha$ phase.

- Electrical resistance measurement proved to be a very sensitive technique for determination of the kinetics phase transformations in metastable $\beta$-Ti alloy.

\section{ACKNOWLEDGEMENTS}

This work was financially supported by the Ministry of Education, Youth and Sports, project LTARF18010. Financial support by the Czech Science Foundation (project no.: 17-04871S) and by ERDF (project no: CZ.02.1.01/0.0/0.0/15.003/0000485) is also gratefully acknowledged. 


\section{REFERENCES}

[1] LÜTJERING, G and WILLIAMS, J.C. Titanium. Berlin, Heidelberg: Springer, 2007. p. 379.

[2] EISENBARTH, E., VELTEN, D., MÜLLER, M., THULL, R., and BREME J. Biocompatibility of $\beta$-stabilizing elements of titanium alloys. Biomaterials. 2004. vol. 25, pp. 5705-5713.

[3] DONACHIE, M.J. Titanium: a technical guide. ASM International, 2000.

[4] LEYENS, C. and PETERS, M. Titanium and titanium alloys: fundamentals and applications. Weinheim: Wiley$\mathrm{VCH}, 2003$. pp. 37-57.

[5] SILCOCK, J.M., DAVIES, M.H., and HARDY, H.K. Structure of the $\omega$-precipitate in titanium-16\% vanadium alloy. Institute of Metals. Monograph and report series. 1955. vol. 18, pp. 93-105.

[6] DE FONTAINE, D. Mechanical instabilities in the b.c.c. lattice and the beta to omega phase transformation. Acta Metallurgica. 1970. vol. 18, pp. 275-279.

[7] PRIMA F., VERMAUT, P., TEXIER G., ANSEL, D., and GLORIANT, T. Evidence of $\alpha$-nanophase heterogeneous nucleation from $\omega$ particles in a $\beta$-metastable Ti-based alloy by high-resolution electron microscopy. Scripta Materialia. 2006. vol. 54, pp. 645-648.

[8] DEVARAJ, A., NAG, S., SRINIVASAN, R., WILLIAMS, R.E.A., BANERJEE, S., BANERJEE, R., and FRASER, H.L. Experimental evidence of concurrent compositional and structural instabilities leading to $\omega$ precipitation in titanium-molybdenum alloys. Acta Materialia. 2012. vol. 60, pp. 596-609.

[9] BANERJEE, S. and MUKHOPADHYAY, P. Phase transformations: examples from titanium and zirconium alloys. Oxford: Elsevier/Pergamon, 2007.

[10] NAG. S., BANERJEE, R., and FRASER, H.L. Microstructural evolution and strengthening mechanisms in Ti-NbZr-Ta, Ti-Mo-Zr-Fe and Ti-15Mo biocompatible alloys. Materials Science and Engineering: C. 2005. vol. 25, pp. $357-62$.

[11] VALIEV, R.Z., ISLAMGALIEV, R.K, and ALEXADROV, I.V., Bulk nanostructured materials from severe plastic deformation, Progress in Materials Science. 2000. vol 45, pp. 103-189.

[12] VALIEV., R.Z., ESTRIN, Y., HORITA, Z., LANGDON, T.G., ZECHETBAUER, M.J. and ZHU, Y.T. Producing bulk ultrafine-grained materials by severe plastic deformation, JOM. 2006. vol. 58, pp. 33-39.

[13] ESTRIN, Y. and VINOGRADOV, A. Extreme grain refinement by severe plastic deformation: a wealth of challenging science. Acta Materialia. 2013. vol. 61, pp. 782-817.

[14] ZHILYAEV, A.P., NURISLAMOVA, G.V., KIM, B.K., BARO, M.D., SZPUNAR, J.A. and LANGDON, T.G. Experimental parameters influencing grain refinement and microstructural evolution during high-pressure torsion, Acta Materialia, 2003. vol. 51, no. 3, pp. 753-765.

[15] EDALATI K. and HORITA, Z. A Review on high-pressure torsion from 1935 to 1988. Materials Science and Engineering A. 2016. vol. 652. pp. 325-352.

[16] ŠmilaUeROVÁ, J., HARCUBA, P., KRIEGNER, D., JANEČEK, M. and HOLÝ, V. Growth kinetics of $\omega$ particles in $\beta$-Ti matrix studied by in-situ small angle X-ray scattering. Acta Materialia. 2015. vol. 100. pp. 126-134.

[17] ZHÁŇAL, P., HARCUBA, P., HÁJEK, M., SMOLA B., STRÁSKÝ, J., ŠMILAUEROVÁ, J., VESELÝ, J. and JANEČEK, M., Evolution of $\omega$ phase during heating of metastable $\beta$ titanium alloy Ti-15Mo, Journal of Materials Science, 2018. vol. 53, no. 1, pp. 837-845.

[18] VÁCLAVOVÁ, K., STRÁSKÝ, J., ZHÁÑAL, P., VESELÝ, J., POLYAKOVA, V., SEMENOVA, I. and JANEČEK, M. Ultra-fine grained microstructure of metastable beta Ti-15Mo alloy and its effects on the phase transformations. IOP Conference Series: Materials Science and Engineering. 2017, vol. 194, no. 1, p. 012021.

[19] HÁJEK, M., VESELÝ, J., and CIESLAR, M. Precision of electrical resistivity measurements. Materials Science and Engineering: A, 2007. vol. 462, no. 1, pp. 339-342.

[20] BARTHA, K., Phase transformations in ultra-fine grained titanium alloys, $\mathrm{PhD}$ thesis, Prague: Charles University, 2019.

[21] ROSSITER, P.L. The Electrical Resistivity of Metals and Alloys. Cambridge University Press, 1987.

[22] NG, H.P., DEVARAJ, A., NAG, S., BETTLES, C., GIBSON, M., FRASER, H., MUDDLE, B. and BANERJEE, R. Phase separation and formation of omega phase in the beta matrix of a Ti-V-Cu alloy, Acta Materialia, 2011, vol. 59, no. 8, pp. 2981-2991. 
[23] SUN, F., PRIMA, F. and T. GLORIANT, T. High-strength nanostructured Ti-12Mo alloy from ductile metastable beta state precursor. Materials Science and Engineering: A, 2010. vol. 527, no. 16, pp. 4262-4269, Jun. 2010.

[24] DEVARAJ, A., WILLIAMS, R.E.A., NAG, S.R., SRINIVASAN, R.H., FRASER, H.L. and BANERJEE, R. Threedimensional morphology and composition of omega precipitates in a binary titanium-molybdenum alloy. Scripta Materialia, 2009. vol. 61, no. 7, pp. 701-704.

[25] LEGROS, M. and DEHM, G. Observation of Giant diffusivity along dislocation core. Science. 2008. vol. 319. pp. 1646-1649.

[26] BARTHA, K., STRÁSKÝ J., JANEČEK, M. et.al, Phase transformations and lattice defects in ultra-fine grained Ti15Mo alloy processed by ECAP and HPT, Materials Characterization. 2019. in press. 